\title{
Fotografando a geringonça sem freio: breve investigação sobre as transformações da música em Brasília desde os anos $\mathbf{8 0}$
}

\author{
André Luiz Fernandes Cunha*
}

Resumo: Inspirado na imagem de uma carroça futurista, criada pela banda Feijão de Bandido em 2001, esse artigo pretende fotografar a cena musical em Brasília dos anos 80 até a atualidade considerando sua natureza arcaica e moderna, global e local simultaneamente. Serão utilizados alguns conceitos desenvolvidos por Stuart Hall no livro A Identidade Cultural na Pós-Modernidade, como hibridismo, nomadismo e multiculturalismo.

Palavras-chave: Brasília; Música; Hibridismo.

Abstract: Inspired by the image of a futuristic wagon created by the band Feijão de Bandido in 2001, this article intends to photograph the musical scene in Brasilia from the 80 s to the present day considering its archaic and modern, global and local nature simultaneously. Some concepts developed by Stuart Hall's book The Cultural Identity in Postmodernity will be used, such as hybridism, nomadism and multiculturalism.

Keywords: Brasília; Music; Hybridism.

\footnotetext{
* Mestre em História Cultural pela Universidade de Brasília
} 


\section{“Como é que eu faço pra parar essa geringonça?"}

"Estou andando no escuro / Na carroça do futuro / Como é que eu faço pra parar essa geringonça?” pergunta a banda Feijão de Bandido na música Carroça do Futuro, do disco Brasil Século XXI: Feijão pra todos! lançado em 2001, onde mistura ritmos como o pop-rock, xote, baião, reague, frevo e salsa, entre outros. O primeiro verso transmite um sentimento de desorientação recorrente na pós-modernidade, marcada também por rupturas, deslocamentos e descontinuidades (HALL, 2002: 17). O segundo revela um anacronismo: uma carroça (segundo o dicionário Aurélio um carro grosseiro, geralmente de tração animal, para cargas) do futuro (tempo que há de vir, porvir, em geral associado a sonhos utópicos e pesadelos distópicos).

O híbrido temporal criado pelo Feijão de Bandido, ela própria uma banda híbrida, egressa de uma cena heterogênea chamada nos anos noventa de "novos calangos", que incluía bandas como A Tuba Antiatômica do Planalto, Xalé Verde e Corindó, não poderia dar em outra coisa: uma geringonça (objeto ou coisa malfeita e de duração precária). Levando em conta que um objeto cultural híbrido implica ideias de fratura, deslocamento e transitividade e que se manifesta através de uma "junção de temporalidades" (VARGAS, 2007: 63 - 64), a geringonça parece descolar-se em alta velocidade entre o arcaico e o moderno, o futuro e o passado.

Geringonças, trambolhos, gambiarras e cacarecos são palavras comuns em nossos vocabulários e se referem em geral a algo sucateado, obsoleto, o qual não se sabe bem como funciona. Nem todos os sentidos de "geringonça", porém, são pejorativos. Também entendida como um aparelho ou mecanismo de construção complexa, pode referir-se à objetos como zepelins, escafandros e outras engenhocas fabulosas. Eleita a palavra do ano em 2016 numa votação promovida pela editora portuguesa Porto Editora, a frente de concorrentes como brexit, parentalidade, microcefalia e empoderamento, foi o termo mais usado no país ao longo do ano para definir o governo de coalizão formado por esquerdistas e ambientalistas no parlamento. ${ }^{1}$

\footnotetext{
${ }^{1}$ Disponível em: https://www.portoeditora.pt/noticias/geringonca-eleita-palavra-do-ano-2016/117782. Acesso
} em 27 de nov. 2017. 
Se analisada à luz das ferramentas da História Cultural (CHARTIER, 1987; PESAVENTO, 2003; BURKE, 2008), que investigam as formas, os conteúdos, os códigos de expressão e os sistemas de representação dos objetos produzidos pelo engenho humano, a geringonça sonora em questão pode, considerados certos elementos como letra, harmonia e instrumentação, refletir uma variedade de sentidos e significados.

"Que eu vejo a crise da ciência / O esgotar da paciência / Vejo o mundo inteiro inchar" continua letra, reforçando o sentimento de desorientação explícito no primeiro verso e apresentando cenários cada vez mais problemáticos: "Na poeira do cerrado / E não sei mais pra que lado / Que eu devo atirar." Mais adiante algumas referências históricas podem ser encontradas, como a chegada em massa ao mercado de grãos geneticamente modificados, o advento da Estação Espacial Internacional em 1998 e o caso da ovelha Dolly, primeiro mamífero clonado a partir de uma célula adulta, em 1996: "É soja transgênica / Revolução na genética / É tanta coisa polêmica / Valores além da estética / É cidade espacial / Ovelha clonada."

Acachapada pela quantidade de coisa polêmica encontrada no mundo, transportada por uma geringonça desgovernada, espécie de metáfora da música candanga, a banda termina a canção com a seguinte constatação: "A coisa não está tão mal / Eu só não entendo nada."

\section{"Ninguém respeita a Constituição"}

Referências inescapáveis quando o tema é o cenário musical na cidade, bandas como Legião Urbana, Plebe Rude, Capital Inicial e Paralamas do Sucesso, já descritas como representantes da "era de ouro" do rock brasiliense no documentário Rock Brasília - Era de Ouro, de Vladimir Carvalho, verbalizavam os dilemas enfrentados pela geração dos anos 80 . Maior banda da história da história de Brasília, cidade cuja memória se estruturou em torno de enunciados míticos de integração nacional como "chamado/chamamento, atração, bandeirante, eldorado, coração da pátria, nova era, arca salvadora" (CARVALHO, 2001: 175), a Legião Urbana arrastava legiões de seguidores e seu aspecto místico e até mítico é inegável.

Será, do disco de estreia da Legião Urbana lançado em 1985, parecia ecoar a frustração pelo fracasso da campanha Diretas Já em 1984: “Será que nada vai acontecer? / Será que é tudo isso em vão? / Será que vamos conseguir vencer?” Já Geração Coca-Cola, 
apesar de fazer uma crítica à colonização cultural norte americana - "Quando nascemos somos programados / A receber o que vocês / Nos empurraram com os enlatados / do U.S.A de nove às seis" -, vale-se de um formato "enlatado" do rock convencional: estrofes com quatro versos, refrão - "Somos os filhos da revolução / Somos burgueses sem religião / Somos o futuro da nação" - e a típica sonoridade roqueira, no caso do Legião influenciada pelo rock gótico inglês de bandas como The Cure e The Smiths.

Também chamada de "década perdida" em função da estagnação econômica, da hiperinflação e do aumento dívida externa, a década de 80 foi repleta de bandas politizadas, mas poucas tão bem-sucedidas quanto a Legião Urbana, que não só vendeu mais de trinta milhões de discos como cunhou hinos que passariam fazer parte da paisagem musical brasileira. Que País É Este? cantada em tantas ocasiões com fervor quase religioso, retrata um país esculhambado - "Nas favelas, no Senado / Sujeira pra todo lado" - e critica a hipocrisia dos brasileiros: "Ninguém respeita a Constituição / Mas todos acreditam no futuro da nação."

Tal futuro é naturalmente inviável. Não por acaso o maior sucesso da Plebe Rude, principal representante da cena punk na capital, se chama justamente Até Quando Esperar, espécie de manifesto contra a lentidão das transformações sociais e políticas: "Até quando esperar / A plebe ajoelhar / Esperando a ajuda de Deus?"

\section{"Mony mucho bom"}

"Nem todos os novos roqueiros pós-Legião Urbana se identificam com o chamado Rock Brasília" afirma Clodomir Souza Ferreira em sua pesquisa sobre a cena musical brasilense. De fato, as transformações ocorridas nos anos 90 - o colapso do comunismo, a internet, a globalização em larga escala - permitiram um intercâmbio multicultural extraordinário e novas questões estéticas e ideológicas surgiram. "O liquidificar típico dos anos 1990" escreve, "permitia a mistura de estilos. Os festivais não procuravam uniformizar os estilos, mas, ao contrário, queriam diversificar o máximo possível, de forma que todas as tribos eram igualmente prestigiadas" (FERREIRA, 2008: 67).

E se a geração Coca-Cola, simbolizada pelo refrigerante mais vendido no mundo, se apropriava de formatos já consagrados - à exceção talvez dos Paralamas do Sucesso, que começavam a inserir pitadas de reague e ska nas suas composições -, a geração seguinte foi definida por uma bebida também açucarada e gaseificada, mas com um componente 
tipicamente brasileiro: o guaraná, fruta nativa da Amazônia que alcançou projeção nacional graças ao Guaraná Baré, em referência a uma tribo que se estendia, no período colonial, de Manaus até o alto do Rio Negro.

"Baré” inspirou o título de Geração Baré-Cola - Usuários de Rock, documentário de Patrick Grosner, que explica assim o motivo da escolha ao Correio Braziliense: "O nome uma antiga marca de refrigerante - faz um contraste com a geração do rock de Brasília da década anterior, a Geração Coca-Cola." Ainda segundo o diretor, "Nos anos 80, a coisa era um pouco mais calcada nas influências estrangeiras. A galera que veio depois, além de se preocupar mais com a originalidade, olhava mais para o Brasil. As pessoas queriam misturar sonoridades para fazer uma coisa nova."

A música brasileira já havia manifestado outras formas de hibridismo, entendido aqui como "um conceito polifônico e dialógico" e "um processo selvagem que rompe estabilidades teóricas, recepções padronizadas e esperanças de unidade semântica" que "mostra-se docemente criativo por ter em si germes de novas alternativas para novas combinações" (VARGAS, 2007: 65). Dois exemplos seriam o rock rural de Sá, Rodrix \& Guarabira e o samba roqueiro dos Novos Baianos. Não só a brasileira: “A música popular latino americana (...) faz-se de sua conformação em mesclas e sobreposições de elementos arcaicos e modernos, nacionais e estrangeiros" valendo-se de "fusões da harmonia tonal europeia e das polirritmias e melodias modais dos africanos e indígenas." (op. cit. 62, 63).

Mas, em função da explosão demográfica no Distrito Federal nos anos 90, as possibilidades criadas pelo intercâmbio multicultural entre nordestinos, paulistas, baianos, mineiros, cariocas, gaúchos, capixabas e muitos outros no mesmo quadrado se multiplicaram. E apesar de manter uma média razoável de bandas temáticas no cenário nacional (Natiruts e Maskavo no reague, GOG e Câmbio Negro no rap, Capital Inicial no pop rock, Plebe Rude no punk, DFC e Os Cabeloduro no hardcore, Lucy and the Popsonics no eletropop e Little Quail and The Mad Birds se revezando no blues, rockabilly e hardcore) e de conservar uma sólida cena do metal pesado (P.U.S, Dungeon, Fallen Angel), Brasília produziu também o seu quinhão de hibridismo.

Umas das bandas mais plurais citadas no filme de Grosner são Os Cachorros das Cachorras, que em 1997 lançou um disco homônimo misturando soul, jazz, samba-rock e 
frevo e se valendo de um respeitável naipe de metais como trombones, trompetes e vários saxofones. Com letras safadas que pouco lembravam os hinos idealistas da geração anterior, a cachorrada abriu o disco com Ragga Mony: "Mony (money, dinheiro) é bom, mony mony mutcho bom.” E replicou os medalhões da música popular brasileira Caetano Veloso e Tim Maia, respectivamente em Beleza Pura e Não Quero dinheiro: "Beleza pura, dinheiro sim / Quando a gente ama também pensa em dinheiro / Se a grana não rolar não dá pra tocar o puteiro."

Se tais letras parecem menos politizadas que as da geração anterior talvez sejam no sentido institucional de política, afinal a democracia fora restaurada e "as ilusões foram todas perdidas" como Cazuza já tinha profetizado. Nas relações de gênero e raça, no entanto, os conflitos se expandiram. Ou, como afirma Stuart Hall em A Identidade Cultural na PósModernidade, as identidades clássicas (nacionalidade, classe social) se fragmentaram e outras identidades (feminismo, movimento negro e ecológico) surgiram (Cf. HALL, 2002).

\section{"Ouça o que o paraíba féla da puta aqui tem pra dizer"}

De todos os gêneros híbridos surgidos na década de noventa, como o funk metal (funk com heavy metal), o rapcore (rap com hardcore) e o Maguebeat (maracatu com guitarra elétrica), o forrocore (forró com hardcore) foi um dos mais criativos. Mistura improvável do mais brasileiro dos ritmos com a variação mais envenenada do rock, o forrocore ganhou o Brasil com os Raimundos.

Principal representante do gênero, a banda (referência aos Ramones, clássico do punkrock norte-americano, e ao nome Raimundo, comum no Nordeste) lançou seu primeiro disco em 1994, catapultado pelo selo Banguela Records, inovando não só na forma, mas também no discurso: "Ouça o que paraíba féla da puta aqui tem pra dizer" declaram em Rapante. Fustigado pelos efeitos de uma "pedra" (merla? crack? rapadura?), o "eu-poético" da música espreita perigosamente as mulheres pelas ruas - "Menina linda na parada de baú / Se eu te pego meio tocada acho que vou comer teu cu" - e produz metáforas escatológicas - "O rabo arranca e o peido avoa / Ninguém para de cagar.” Violência sexual, escatologia, pornografia, apologia às drogas, parece não haver filtro algum nas canções dos Raimundos.

Em 1995, com Lavô tá Novo, a banda emplacou hits como a pornográfica Tora Tora "Então se abaixa e chupa a rola agora" e a niilista "Eu Quero ver o Oco", maior sucesso da

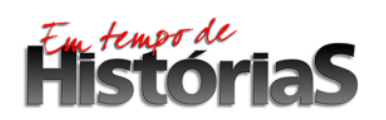


banda e espécie de relato sádico-perverso sobre um acidente de carro - eis aí outro veículo desgovernado.

Na categoria palavrão por metro quadrado o destaque é Esporrei na Manivela, que só na primeira estrofe contém meia dúzia de palavras ou expressões obscenas - "esporrei", "filha-da-puta", "caralho", "escrota", "cu", "viado" - e na sequência confessa uma tara repugnante: "O coletivo é muito bom para sarrar / Pois o povo aglomerado sempre tende a se esfregar / Com as nega véia é perna aqui perna acolá / E se a xereca é mal lavada faz a ricota suar" levando em conta que "no que coletivo o que vale é a lei do pau."

Se por um lado é verdade que piadas envolvendo assédio no transporte público já não são mais toleradas pela sociedade - se lançada hoje em dia tal letra fatalmente provocaria intensos questionamentos nas redes sociais -, por outro convém lembrar que nem todas as letras dos Raimundos são machistas (embora boa parte parte seja de fato obscena) e que nos anos noventa uma certa pulsão juvenil inconsequente, espécie de refluxo pós redemocratização, fazia parte da cena musical: o rapper Gabriel o Pensador insultou o Presidente da República, os Paralamas do Sucesso insultaram o Congresso Nacional, o Planet Hemp (Planeta Maconha) insultou a Polícia Militar e a banda de hardcore Os Cabeloduro insultou e agrediu todo mundo em músicas como Ódio Sem Razão, Enfia no Cu, Foda-se e Cala a Boca Animal do disco Com Todo Amor e Carinho, de 1996.

\section{"Sou negão careca da Ceilândia mermo e daí?"}

Quando o Feijão de Bandido cantava que via "o mundo inteiro inchar" provavelmente se referia aos grandes fluxos migratórios transnacionais da contemporaneidade, as chamadas novas diásporas pós-coloniais, processos contínuos e em grande escala, que envolvem questões de Tradição e Tradução cultural no contexto do nomadismo (HALL, 2002: 82 - 89), mas também aos fluxos regionais responsáveis pela expansão das periferias nas metrópoles brasileiras. E a periferia de Brasília fez parte desse processo.

A origem do nome "Ceilândia", região administrativa do Distrito Federal, não é nada romântica. Criada nos anos 70 com o objetivo de legalizar lotes irregulares ao norte de Taguatinga, a Campanha de Erradicação de Invasões (CEI) demarcou mais de vinte mil lotes em assentamentos largamente desprovidos de serviços públicos. À estrovenga administrativa foi acrescentado o sufixo "lândia." Uma legítima geringonça.

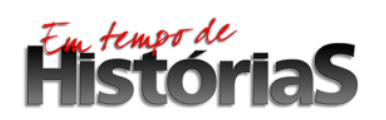


Descrita, nos anos 90, pela banda de rap Câmbio Negro, como "Terra sem lei, nova babel, casa do caralho" na música Ceilândia Revanche do Gueto, a cidade satélite é hoje, com cerca meio milhão de pessoas, o subúrbio mais densamente povoado do Distrito Federal. O retrato pintado pela banda é sombrio: "Mais de 500 mil e pra eles somos lixo / Lutando pra sobreviver, tratados como bichos / Escrotos ratos de esgotos, vermes rastejantes / Cobras, bichos peçonhentos, monstros repugnantes."

Apesar do preconceito e das condições precárias de sobrevivência, a identidade, aqui, é afirmada com orgulho. Na música A Volta o "lugar de fala", grosso modo o discurso de quem sofre preconceito, sem mediação, fica explícito: "Sou negão careca da Ceilândia mermo e daí?" Há empoderamento racial - "sou negão" -, estético - "careca" -, regional - "da Ceilândia" - e linguístico - "mermo" sendo a versão popularmente falada do adjetivo "mesmo" - logo no primeiro verso. Há, ainda, uma clara demarcação de território: “e daí?"

Em Esse é o Meu País a banda imagina um porvir maravilhoso que se estende por centenas de anos no futuro: um Brasil onde há igualdade racial, policiais educados, direitos garantidos, mulheres no governo, negros no senado, cientistas reconhecidos, oportunidades de emprego, moradia e aposentadoria dignas. O refrão não poderia ser mais irônico: “Aqui é o nosso país / Brasil, primeiro mundo, todo mundo feliz."

\section{"Mulher não é boneca nem capacho de machista"}

Pollyana, a personagem criada pela escritora norte-americana Eleanor H. Porter, que costumava jogar o "jogo do contente" - ver o lado positivo até das coisas mais desagradáveis -, está morta. Pelo menos no que depender da banda Poliana is Dead que, dentro da estética Riot Grrrl, movimento que aproxima o feminismo da cultura pop, mistura sonoridades punk, grunge e alternativa. Descrito por Hall tanto como uma crítica teórica quanto um movimento social, o feminismo "faz parte daquele grupo de novos movimentos sociais que emergiram durante os anos sessenta (o grande marco da modernidade tardia), juntamente com as revoltas estudantis, os movimentos contraculturais e antibelicistas, a luta pelos direitos civis" e por fim “tudo aquilo que está associado com 1968” (HALL, 2002: 44).

Conhecido como "o ano que não terminou" e simbolizado por slogans como "quanto mais eu faço amor, mais tenho vontade de fazer a revolução" e "é proibido proibir" (nome de uma música de Caetano Veloso, figura influente no movimento),1968 inaugurou, nessa 
perspectiva, uma nova política das identidades que questiona a distinção entre o dentro e o fora, o público e o privado, e que pode ser resumida na frase "o pessoal é político." (HALL, 2002: 44).

Na música Fica Esperta, depois de descrever um personagem que bem poderia ter saído de uma música dos Raimundos - "naquela van lotada um cara te bolina" -, a banda conclama: "Mulher não é boneca nem capacho de machista / Eu, ela, todas unidas / Lutar por nosso espaço ou estaremos fodidas!"

Já em Orgulho do Brasil a banda Bulimia levanta uma bandeira abominável - "Nós apoiamos a prostituição infantil" - e declara uma influência no mínimo esquisita - "Nós somos É o Tchan do Brasil" -, sendo É o Tchan uma banda de axé e pagode popular nos anos 90. A ironia aí é tão cristalina quanto a do Câmbio Negro em Esse é o Meu País: com suas dançarinas hipersexualizadas, estereótipos de gênero e letras frívolas, o grupo É o Tchan representa o exato oposto estético e ideológico da banda Bulimia (punk, politizada, feminista, inconformista).

Mas se o rock sempre teve um viés inconformista - a crítica à massificação midiática em Geração Coca-Cola, os alunos virando salsicha no icônico videoclipe Another Brick in The Wall, do Pink Floyd, as letras questionadoras de Bob Dylan, e tantos outros exemplos -, o inconformismo do Bulimia, da Poliana is Dead e outras bandas feministas da cidade se volta em geral para questões de gênero. A crítica aos papéis e valores estabelecidos pela sociedade, aqui, encontra as questões colocadas pelo feminismo: "Não importa se acham bonito ou feio uma garota dar em cima de alguém / É a sua vida / Não importa se acham bonito ou feio uma garota exercer certas atividades / É a sua vida / Lute por ela!"

Se, como sugere Hall, o feminismo politizou a subjetividade e a identidade feminina, é possível ler interpretar os versos seguintes não só como um questionamento social e político contra o machismo e o patriarcado, mas também como um questionamento psicológico diante da vida: "Não deixem que seus sonhos se tornem lembranças de uma dona de casa passiva e submissa!" cantam as mulheres do Bulima em Lute Pela Sua Vida.

\section{"Dancem feito os nossos índios"}

Em oposição ao processo de homogeneização cultural promovido pela globalização surge, nos anos 90, com ênfase nas origens, continuidade, tradição e intemporalidade (HALL, 
2002: 53), um poderoso revival das culturas locais. Com influência de antigas correntes estéticas como o arcadismo (exaltação da natureza) e a primeira geração o romantismo (o índio como símbolo das nossas raízes), esse revival busca, em sintonia com os protestos antiglobalização e uma crescente expansão do movimento ecológico, uma nova articulação, menos assimétrica, entre o global e o local, resultando numa cultura "glocal" ao mesmo tempo resgatada e (re)inventada.

Brasília não foi exceção. Situada geograficamente no coração do Goiás, onde, segundo o Feijão de Bandido em Águas do Cerrado, "um banho de cachoeira veste o Planalto Central", a cidade, cercada por lugares paradisíacos - o circuito Pirenópolis \& Chapada dos Veadeiros -, produziu toda uma cultura roots (do inglês raízes) repleta de sonoridades indígenas, de referências envolvendo cristais, ipês coloridos, animais do cerrado (tatu, lobo guará, calango) e cachoeiras. Na canção transbordam nomes fantásticos como Poço Azul, Topázio, Tororó, Raizama, Vale da Lua, Salto de Corumbá, Quebrada dos Deuses e Cachoeira do Altar.

Dessa interseção entre música, folclore e ambientalismo surgiu todo um circuito de festivais, feiras e eventos ecológicos onde se apresentavam bandas e grupos roots como o Casa de Farinha (só percussão e vozes femininas, cantigas de roda antiquíssimas, com centenas de anos) e o Amanita Muscaria (nome inspirado num cogumelo alucinógeno, influências de rock, reague, ska e um discurso claramente pró-sustentabilidade e conservacionista). Em Governos Ecosuicidas a banda se exaspera com as queimadas das florestas, o derretimento das calotas polares, a fumaça dos carros, o lixo dos rios, o uso de pesticidas, o buraco na camada de ozônio, e faz um prognóstico sombrio: "Pela água será a nova guerra." Aqui o futuro reflete uma consequência direta das nossas ações sobre o meio ambiente: "O desafio para o futuro é evitar um final prematuro."

Outra banda que deu à essa consciência ambiental uma forma estética foi o Ha-OnoBeko que, usando instrumentos confeccionados a partir de materiais recicláveis (arame, cipós, tubos de PVC) e figurino feito à base de pneus, corda e bambu, e misturando música afro, tribal e indígena com baião, levadas de funk e groove, lembra uma carroça eletrônica de sucata. Ciranda, batuques, chulas e quadras de capoeira se misturam ao som da parafernália 
sonora. Nessa viagem "do mundo primitivo ao mundo moderno" o grupo busca "resgatar o espirito coletivo dos povos indígenas e o ritmo dos tambores africanos." 3

Influenciado por grandes mestres da música brasileira como Luiz Gonzaga, Hermeto Pascoal, Quinteto Violado e Antônio Nóbrega, o Pé de Cerrado, ao misturar sonoridades indígenas, sertanejas, africanas e referências ao folclore brasileiro, reforça a identidade regional enquanto verbaliza mensagens ecumênicas de não-violência, fraternidade e amor à natureza. O "som do cerrado" produzido pela banda é cheio de vibrações positivas, como pode ser constatado na letra de Oração: "Reverencie ao sol / Cante pras ondas do mar / Toque para irmã lua / E deixe a fogueira queimar / Na união das nossas mãos / Com calor e com pureza / Dancem feito os nossos índios / Adorando a natureza."

\section{"Não me importaria em migrar pra Marte"}

Em 2001, ano em que Carroça do Futuro foi lançada, dois aviões, imensos engenhos modernos pilotados por fundamentalistas religiosos, chocaram-se contra as Torres Gêmeas no centro de Nova York, numa espécie de prelúdio sanguinário do terceiro milênio, aumentando a sensação generalizada de imprevisibilidade. Levando em conta que "se somássemos todas as descobertas científicas, invenções e inovações técnicas realizadas pelos seres humanos desde as origens até hoje, chegaríamos à espantosa conclusão de que mais de oitenta por cento delas se deram nos últimos cem anos" (SEVCENKO, 2001: 24), o século XXI se afigura virtualmente imprevisível e espantosamente tecnológico.

Paralelo ao som pacifista e regional de bandas como o Pé de Cerrado a cidade produziu um outro tipo de som mais cosmopolita, antenado com as ferramentas do pósmodernismo, como ironia, sátira, pastiche, colagem e multiculturalismo: “As melhores bandas são as de abertura / A cena mais bacana é a indie folk da Albânia" canta o Lucy and The Popsonics em Biff Bang Pop. O grau de especialização impressiona. A “cena mais bacana”, ou seja, onde, neste exato momento, se fazem as melhores músicas, é a independente (indie), folclórica (folk) e da Albânia (um país do leste europeu). Até a próxima moda, afinal "A cada 10 segundos cai um single na internet / E a cada 2 minutos um novo podcast."

Algumas patologias tipicamente urbanas podem ser encontradas nas letras da banda, como ansiedade em A Síndrome das Pernas Inquietas - "Não aguento ir ao dentista / Não

\footnotetext{
${ }^{3}$ Disponível em: http://www.haonobeko.tnb.art.br/ Acesso em 27 nov. 2017. 
suporto esperar uma pizza / Sempre acho que vai estourar meu coração" -, a sensação de falta de tempo - "Como eu gostaria que a vida fosse lenta / Sobraria o tempo pro meu imposto de renda" - e falta de sono - "Não me importaria em migrar pra Marte / Aproveitaria pra dormir mais até tarde" - em Multitarefa e mania de perseguição em Fred Astaire: "Vivo numa maquete / Me sinto um rato branco / Sou um experimento / Trabalho em um banco."

Expostos à precarização das relações de trabalho, os jovens da Geração Z, também chamada de iGeneration em referência ao prefixo "i" onipresente nos produtos da Apple, parecem frustrados: "Já não sei mais como se faz / Aos trinta anos eu moro com meus pais" confessa a banda Sexi Fi na canção Pequeno Dicionário das Ruas, do disco Nunca te Vi de Boa, de 2012, antes de entoar o mesmerizante refrão "boto fe, boto fééé..."

Dois pontos chamam atenção: a sinceridade mórbida - não tão mórbida quanto a dos Raimundos - como o fracasso financeiro é declarado - "Aos trinta anos eu moro com meus pais" -, lembrando o humor tipicamente cínico e autodepreciativo dos grandes centros urbanos, onde milhões de fracassados se solidarizam, e o nome do disco. Nunca Te Vi de Boa equivale dizer que jamais, em tempo algum, aquele a quem o disco é dedicado foi visto "de boa", ou seja, calma, sereno, em paz. Em Looking Asa Sul, Feeling Asa Norte, há de depressão - "Eu vivo na pior" - à dependência química: "Ninguém é normal, não, sem medicação.” O som, no entanto, é adorável.

\section{"A coisa não está tão mal"}

Ultraconectados, com a acesso a cada vez mais informações disponíveis no "supermercado cultural" de que fala Hall, os músicos globalizaram e regionalizaram a música local de formas cada vez mais imprevisíveis. Novas geringonças surgiram. Outros ritmos apareceram. Não só o forró, mas o xote, o coco, o maxixe e o afoxé passaram a frequentar as mesas onde DJs sampleavam uma maçaroca de ritmos, como pode ser conferido no som do Criolina, coletivo de DJs, artistas e produtores culturais da cidade.

"Ao conhecer melhor a história cultural de Brasília, percebe-se que o título de Capital do rock somente se justifica pelo impacto do sucesso das bandas da cidade na década de 1980 no mercado fonográfico nacional" escreve Souza, "mas, do ponto de vista do processo de construção criativa de uma cidade múltipla por natureza, formada pelo cruzamento de ricas 
culturas regionais, vemos que o termo exato é Brasília, capital da diversidade." (FERREIRA, 2008: 145).

Ou seja, Brasília pode não ser a capital do rock, mas não resta dúvida que o rock em Brasília incorporou e foi incorporado por essa diversidade. Sua eclética cena do choro, por exemplo, teria passado por pelo menos três fases: a primeira, muito próxima do choro tradicional carioca; a segunda, investindo numa linguagem harmônica mais contemporânea; e a terceira, "relacionada a elementos do jazz e uma atitude roqueira no palco, ao virtuosismo instrumental e a um estilo improvisatório peculiar”, (CLÍMACO, 2015: 173). Essa evolução extrapola a cena do choro e revela, em relação à cena musical da cidade, "a sua grande interação com o cenário sócio-histórico e cultural acentuadamente híbrido, a sua plena aceitação da diversidade, do plural, o cultivo de bens locais em diálogo com o global.” (op. cit.183).

Tocando uma mistura de rock progressivo, jazz e ritmos brasileiros, o Protofonia, por exemplo, faz parte, junto com o Worsa, Passo Largo e Satanique Samba Trio, de uma nova cena difícil de ser rotulada (Geração iCola?), que atira para todos os lados, como pode ser constatado através releases, encartes e material para a imprensa produzidos por essas bandas.

O Protofonia se define como "um trio de música experimental, um laboratório, um lugar seguro onde os rótulos podem se despir" e os músicos compartilham influências "do jazz em toda as suas vertentes, o rock mais do que progressivo do King Crimsom e Henry Cow, a improvisação livre de Keit Tippett e Ornete Coleman, música erudita contemporânea e eletroacústica." 4

"Mistura de ska, rock clássico, metal, gipsy jazz, blue grass, hard rock, progressivo e outros ritmos brasileiríssimos" é a proposta do Passo Largo.

"Naná Vasconcelos, Arrigo Barnabé, Frank Zappa, Rush e Bjork" são as influências do Worsa em Omoioi, disco conceitual em trinta e três atos. Advertência: "Em certos momentos você vai ter a impressão de ouvir Hermeto Pascoal trocando Ramones."

Já o Satanique Samba Trio, um trio de sambistas satânicos que por sinal é um quinteto, mistura "jazz fusion, samba, bossa nova e rock" e absorve elementos "da musica erudita contemporânea, com dissonâncias e distorções rítmicas."’7

\footnotetext{
${ }^{4}$ Encarte do CD Protofonia (Protofonia). Editio Princeps, 2013.

${ }^{5}$ Presskit da banda Passo Largo. Disponível em: http://www.passolargo.com/ Acesso em 27 de nov. 2017.

${ }^{6}$ Depoimento concedido ao autor e publicado no artigo "Contra o refrão". Revista meiaum, Brasília, p. 48 - 49 , 04 fev. 2014.
} 
Marcada pela volatilidade, fluidez e impermanência das relações sociais (Cf. BAUMAN, 2001), a modernidade líquida é por definição a era da imprevisibilidade. E passar pela experiência de ouvir um disco do Worsa, Protofonia, Passo Largo, Satanique Samba Trio ou tantas outras bandas que misturam uma variedade incrível de estilos - Toro, Etno, Alarmes, Belga, Rios Voadores, Almirante Shiva, Galopardo, Marssal, Dillo, Darshan, Jambalaia, Trampa, Done Cislene, Pollares, Scalene, Bruto Brancunians, Massay, Distintos Filhos, Sinco, Duex, Mdnght Mdnhgt, Horta Project, Selvet, Cachimbó Eletro, Adriah, Ellefante, Rocan, Ellfus, Dog Savana, Di Boresti, Kabula, Detrito Federal, Brown-Há, Galinha Preta, DFC, Kelton, Os Cabeloduro, Cascata, Na Lata, Luanda, Lista de Lily, La Morsa, Zéfiro, Mariana Camelo, K-Libre, O Tarot, Passo Largo, Deceivers, Macakongs 2099, Calvet, Dawn Jones, Surf Sessions, King Void, Paradisi, Cadibóde, Ameno, Vontana ${ }^{8}$ - é tudo menos previsível, uma viagem alucinante numa carroça futurista desgovernada.

\section{"Apenas começamos"}

"O mundo começa agora / Apenas começamos" canta a Legião Urbana ao final de Metal Contra as Nuvens, canção que altera vários ritmos e dura incríveis onze minutos e meio, tamanho fora das convenções comerciais de execução. O tom otimista e inocente do desfecho se contrapõe aos sentimentos intensos verbalizados ao longo da letra, como a busca por independência - "Não sou escravo de ninguém / Ninguém senhor do meu domínio" -, as dificuldades do caminho - "Viajamos sete léguas / Por entre abismos e florestas" -, a desilusão com o próximo - "Quase acreditei na sua promessa / E o que eu vejo é fome e destruição" - e às metáforas de forte apelo místico, como "Eu sou metal, raio, relâmpago e trovão / Eu sou metal, eu sou o ouro em seu brasão." A música pertence ao disco V, de clima sombrio e influências medievais, lançado em 1991, que fazia alusões à crise econômica da era Collor e à relação problemática de Renato Russo com as drogas.

Pelo fato de Brasília ser uma cidade jovem é razoável supor que, mesmo já tendo passado por tantas transformações, a história da sua música popular também esteja apenas começando. Longe da pretensão de esgotar o assunto, ciente de que várias bandas importantes não foram contempladas, o objetivo deste artigo foi fotografar essa fabulosa geringonça que

\footnotetext{
${ }^{7}$ Disponível em: http://www.wikiwand.com/pt/Satanique_Samba_Trio. Acesso em 27 de nov. 2017.

${ }^{8}$ Revista Traços, Julho/2017 Número 18.
} 
se desloca em alta velocidade no tempo e no espaço, sob a impressão, descrita no início do livro Cem Anos de Solidão, de Gabriel Garcia Marquez, clássico da literatura latinoamericana, de que "o mundo era tão recente que muitas coisas careciam de nome e para mencioná-las se precisava apontar com o dedo."

Ao longo de tais apontamentos foram utilizados alguns conceitos trabalhados por Stuart Hall no livro A Identidade Cultural na Pós-Modernidade e alguns pressupostos teóricos contidos no que se convencionou chamar de História do Presente, que não se confunde com o jornalismo, mas não lhe é completamente estranho. Sob a perspectiva dessa linha de pesquisa, que consiste em investigar o passado problematizado por questões vividas no presente (PORTO JR, 2007), espera-se ter conferido algum grau de nitidez à essa fotografia.

\section{Referências bibliográficas}

BAUMAN, Zygmunt. Modernidade Líquida. RJ: Jorge Zahar, 2001.

BURKE, Peter. O que é História Cultural? SP: Jorge Zahar Editora, 2008.

CARVALHO, Iracilda Pimentel. "Brasília: Imagens e Representações - A Fala do Povo.” In: Contar História, Fazer História - História, Cultura e Memória. Brasília: Paralelo 15 Editores, 2001, p. 167 - 180.

CHARTIER, Roger. História Cultural: entre Práticas e Representações. RJ: Difel, 1987.

CLÍMACO, Magda de Miranda. "Interpretação e Improvisação: A Música Instrumental em Brasília sob o Enfoque do Representacional.” In: Música e Contemporaneidade: Ações e Reflexões. GO: Editora da PUC Goiás, 2015, p. 173 - 185.

FERREIRA, Clodomir Souza. Impressões digitais da (in)dependência: Os CDs (in)dependentes em Brasília (1990 a 2007). Tese apresentada ao Programa de Pós-Graduação de História. Departamento de História da Universidade de Brasília, 2008.

HALL, Stuart. A Identidade Cultural na Pós-Modernidade. RJ: DP\&A, 2002.

PESAVENTO, Sandra Jathay. História e História Cultural. BH: Autêntica, 2003.

PORTO JR, Gilson. História do Tempo Presente. SP: Edusc, 2007.

SEVCENKO, Nicolau. A corrida para o século XXI: no loop da montanha russa. SP: Cia das Letras, 2001.

VARGAS, Heron. "O Hibridismo e a Mestiçagem como Instrumentos para o Estudo da Canção na América Latina.” In: Música e Mídia: Novas Abordagens sobre a Canção. SP: Via Lettera Editora e Livraria Ltda, 2007, $61-78$

\section{Referências fonográficas}

A Consciência do Átomo (Protofonia). Editio: Princeps, 2015.

Ambiental Rock (Amanita Muscaria). Independente, 2013.

Brasil Século XXI: Feijão pra todos! (Feijão de Bandido). Independente, 2001.

Círculo Vicioso (Câmbio Negro). Trama, 1998.

Com Todo Amor e Carinho (Os Cabeloduro). RVC, 1996.

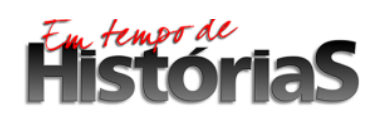


Diário de um Feto (Câmbio Negro). Discovery, 1995.

Férias em Nibiru (Passo Largo). Independente, 2016.

Fica Esperta (Pollyana is Dead). Independente, 2017.

Fred Astaire (Lucy and the Popsonics). Monstro Discos, 2010.

Legião Urbana (Legião Urbana). EMI, 1985.

Lavô Tá Novo (Raimundos). Warner, 1995.

Misantropicalia (Satanique Samba Trio). Amplitude, 2014.

Nunca Te Vi De Boa (Sexi Fi). Far Out, 2012.

O Concreto já Rachou (Plebe Rude). EMI, 1986.

Omoioi (Worsa). Atrator, 2013.

Os Cachorros das Cachorras (Os Cachorros das Cachorras). Independente, 1997.

Pé de Cerrado (Pé de Cerrado). GRV Discos, 2005.

Que País é Este (Legião Urbana). EMI, 1987.

Protofonia (Protofonia). Editio Princeps, 2013.

Raimundos (Raimundos). Banguela Records, 1994.

Siga o Sol e Vá em Frente (Ha-Ono-Beko). Independente, 2000.

Se Julgar Incapaz Foi o Maior Erro que Cometeu (Bulimia). Protons, 2001.

V (Legião Urbana). EMI, 1991.

\section{Referências cinematográficas}

Geração Baré-Cola - Usuários de Rock. Patrick Grossner, Corfilmes, Brasil, 2014.

Rock Brasília - Era de Ouro. Vladimir Carvalho, DownTown Filmes, Brasil, 2011.

\section{Revistas e endereços eletrônicos}

Revista meiaum, Brasília, 04 fev. 2014

Revista Traços, Julho/2017 Número 18

https://www.portoeditora.pt/noticias/geringonca-eleita-palavra-do-ano-2016/117782

http://www.correiobraziliense.com.br/app/noticia/diversao-e

arte/2014/11/20/interna_diversao_arte,458354/filme-geracao-bare-cola-revive-o-panorama-musical-dos-anos1990-em-brasilia.shtml

http://www.haonobeko.tnb.art.br/

http://www.passolargo.com/

http://www.wikiwand.com/pt/Satanique_Samba_Trio 